\title{
IMPLEMENTASI CONTINUOUS IMPROVEMENT DENGAN MENGGUNAKAN METODE PDCA PADA PROSES HANDOVER DI WAREHOUSE PT. ABC
}

\author{
Tri Widodo ${ }^{\text {) }}$, Ismail Fardiansyah ${ }^{2)}$ \\ ${ }^{1,2)}$ Program Studi Teknik Industri, Fakultas Teknik \\ Universitas Muhammadiyah Tangerang \\ Jl. Perintis Kemerdekaan I/33 Cikokol, Kota Tangerang \\ E-mail : tiga_wd@yahoo.co.id, fardiansyahismail@yahoo.com
}

\begin{abstract}
A b s tract
Culture of continuous improvement are favorite things that implemented in many business. This is also as concern in PT.ABC to apply continuous improvement in their operations. They use PDCA (Plan, DO, Check, Action) methodologies to solve the problem. One of PDCA case study that to be a topic for this research are problem solving in handover process.

Lead time for handover process are 20 hours, it will be bring another negative effect. So, problem solving by using PDCA methodologies are conducted. Plan phase are problem Identification, identify cause, and developing solution by using some tools :swim lane flowchart, cause effect diagram, mind mapping effort and benefit matrix. Do phase are execute the action plan, then Check phase are verify the result. The last phase are Action, it is a standardization and next improvement topic .
\end{abstract}

Outcome of PDCA implementing in handover process are reducing lead time in handover process, from 1.161 minutes to 265 minutes, or lead time decreasing by 77\%. Other positive effect of PDCA implementing are facilitate the operator to operate the documents, utilize the space that caused by inventory reducing in staging area.

Key words : PDCA, Swim lane, Cause and effect diagram, Mind mapping, Effort \& benefit diagram.

\section{PENDAHULUAN}

Tujuan utama semua perusahaan adalah menciptakan keuntungan, peningkatan keuntungan dilakukan dengan dua cara, yaitu menaikkan harga jual atau menurunkan biaya. Dikarenakan biaya merupakan indikator penting dalam persaingan di pasar, maka jalan untuk meningkatkan keuntungan adalah dengan cara menurunkan biaya yang dapat dicapai dengan budaya continuous improvement pada operasional perusahaan (Gupta,2013). Menurut lodgaard \& aasland (2011) Plan-Do-Check-Act (PDCA) cycle merupakan metode tingkat tinggi untuk menjalankan continuous improvement yang sudah menjadi elemen dasar dari pergerakan total quality management.

Kovach dkk (2011) dalam penelitiannya menyatakan bahwa PDCA merupakan salah satu jalan yang baik untuk ditempuh guna menghadapi pasar global yang sangat kompetitif.Gidey et al (2014) juga menyimpulkan bahwa PDCA cycle merupakan pendekatan continuous improvement yang sangat mahsyur dan telah banyak digunakan oleh perusahaan yang sukses sebagai senjata strategis untuk meningkatkan performa organisasi.

Pada penelitian yang dilakukan Chakraborty (2016) menjelaskan bahwa pada tahap plan, tools digunakan untuk menggambarkan kondisi saat ini dengan menggunakan SIPOC, flow chart, VSM, pareto, run chart, diagram scatter,brainstorming fishbone, dan 5 Why. Pada tahap Do aktivitas yang dilakukan antara lain : mengimplementasikan improvement, mengumpulkan data dan masalah baru yangmuncul dari hasil percobaan, pembelajaran dari hasil percobaan, serta pengetahuan yang dibutuhkan untuk mengatasi masalah baru yang muncul. 
Loodgard \& Aasland (2011) menyatakan bahwa tahap check adalah tahap untuk mengevaluasi efek dari implementasi yang dilakukan pada tahap Do. Dengan tools yang digunakan antara lain :Pareto, histogram, run chart, scatter plot, dan control chart. Sedangakan pada tahap Action aktivitas yang dilakukan adalah standarisasi proses yang berhasil di improve, dan Knight (2012) juga menerangkan bahwa pada tahap action juga dilakukan startegi improvement selanjutnya, sebagai langkah untuk improvement yang terus menerus.

Salah satu pelanggan yang menggunakan jasa PT.ABC sering mengeluhkan bahwa aktivitas handover antara pihak warehouse dan pihak transporter memiliki waktu yang sangat lama, rata-rata lamanya aktivitas handover sebesar 20 jam per 1 shipment. maka penelitian ini bertujuan untuk melihat bagaimana implementasi continuous improvement menggunakan metode PDCA serta mengetahui bagaimana hasil yang didapatkan terkait permasalahan yang sedang terjadi pada aktivitas handover di proses outbound pada PT.ABCsalah satu pelanggan yang menggunakan jasa PT.ABC sering mengeluhkan bahwa aktivitas handover antara pihak warehouse dan pihak transporter memiliki waktu yang sangat lama, rata-rata lamanya aktivitas handover sebesar 20 jam per 1 shipment. maka penelitian ini bertujuan untuk melihat bagaimana implementasi continuous improvement menggunakan metode PDCA serta mengetahui bagaimana hasil yang didapatkan terkait permasalahan yang sedang terjadi pada aktivitas handover di proses outbound pada PT.ABC.

\section{METODE PENELITIAN}

Penelitian ini dilakukan bersamaan dengan workshop improvement menggunakan metode atau tahapan PDCA sebagai berikut :

Tahap Plan

1. Identifikasi Masalah

Langkah awal yang dilakukan adalah menetapkan masalah dan tujuan. Pada langkah ini ditetapkan apa masalah yang terjadi serta efek yang ditimbulkan dari masalah tersebut. Lalu ditetapkan tujuan, seberapa besar masalah ini akan diselesaikan.

2. Identifikasi Penyebab

Langkah selanjutnya adalah melakukan identifikasi penyebab melalui observasi langsung dilapangan. Fokus pada langkah ini antara lain : mengetahui alur proses saat ini, melakukan pengukuran waktu untuk aktivitas handover, dan meneliti serta melihat potensi improvement dari penyebab-penyebab yang ditemukan.

3. Rancangan Solusi

Selanjutnya setelah penyebab diketahui, maka langkah selanjutnya adalah melakukan brainstorming untuk mencari solusi dari permasalahan yang sedang dialami.

Tahap Do

Pada tahap ini seluruh solusi di eksekusi, sekaligus menganalisa dengan mencatat apakah ada masalah lain yang muncul saat solusi dieksekusi.

\section{Tahap Check}

Tahapan ini adalah memeriksa hasil dari solusi yang diterapkan, dengan melihat apakah leadtime handover sudah menurun sesuai dengan tujuanyang ditetapkan dan menganalisa dampak lain yang terjadi.

Tahap Action

Adalah tahap implementasi dari improvement yang dilakukan, serta tahap untuk memastikan bahwa improvement yang terjadi dapat bertahan. 


\section{HASIL DAN PEMBAHASAN}

\section{A. Identifikasi Masalah}

Masalah yang ditetapkan adalah lamanya waktu untuk aktivitas handover antara pihak warehouse dan pihak transporter memakan waktu hingga 20 jam sehingga menimbulkan efek antara lain :

1. Terjadi complain dari pelanggan dikarenakan proses yang cukup lama

2. Menumpuknya produk pada suatu area

3. Efisiensi yang sangat kecil.

Sehingga tujuan yang ingin dicapai adalah mereduksi leadtime untuk proses handoverantara pihak warehouse dan pihak transportersebesar $50 \%$ pada PT.ABC.

\section{B. Identifikasi penyebab}

Setelah dilakukan observasi dengan melihat alur proses detail aktivitas dan lamanya waktu setiap aktivitas, maka dapat dilihat alur proses aktivitas handover antara pihak warehouse dan pihak transporter adalah sebagai berikut :

\section{Alur proses aktivitas handover}

Alur proses pada aktivitas handover dibuat sedemikian rupa dengan menambahkan data lamanya waktu pada masing-masing step aktivitas handover, serta menambahkan step aktivitas mana yang merupakan aktivitas yang tidak bernilai tambah sehingga memudahkan kita untuk membantu menganalisa. Analisa alur proses pada aktivitashandover dapat dilihat pada gambar dibawah ini:

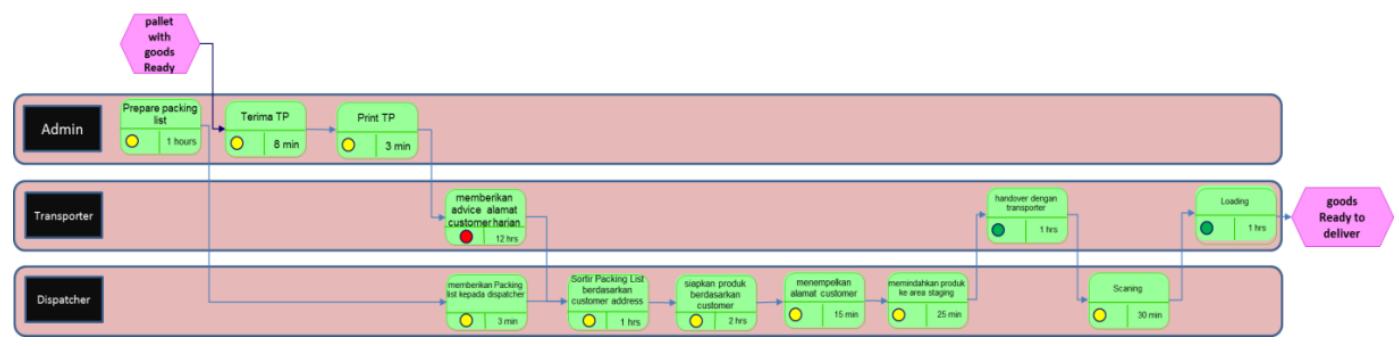

Gambar 1. Alur proses aktivitas handoversebelum improvement

Dari tabel diatas diketahui terdapat step aktivitas yang tidak memberikan nilai tambah, serta aktivitas support maupun aktivitas yang memberikan nilai tambah. Hasil analisa tersebut dapat dilihat pada tabel dibawah ini :

Tabel 1. Analisa step aktivitas handover :

\begin{tabular}{|c|c|c|}
\hline $\begin{array}{c}\text { Aktivitas yang bernilai } \\
\text { tambah }\end{array}$ & $\begin{array}{c}\text { Aktivitas yang tidak bernilai } \\
\text { tambah }\end{array}$ & Aktivitas Support \\
\hline $\begin{array}{l}\text { 1. Handover dengan } \\
\text { transporter } \\
\text { 2. Loading }\end{array}$ & $\begin{array}{l}\text { 1. memberikan advice } \\
\text { alamat daily customer }\end{array}$ & $\begin{array}{l}\text { 1. mempersiapkan packing list } \\
\text { 2. menerima transport planning } \\
\text { 3. memberikan packing list } \\
\text { kepada dispatcher } \\
\text { 4. sortir packing list berdasarkan } \\
\text { alamat customer } \\
\text { 5. menempelkan alamat customer } \\
\text { pada produk } \\
\text { 6. memindahkan produk ke area } \\
\text { staging } \\
\text { 7. scaning }\end{array}$ \\
\hline
\end{tabular}


2. Analisa sebab akibat

Selanjutnya dilakukan barinstorming, untuk melihat step aktivitas mana yang memiliki efek langsung terhadap leadtime proses handover, dan sangat berpotensi untuk dilakukan improvement. Brainstorming ini menggunakan analisa sebab akibat yang dapat dilihat pada gambar dibawah ini :

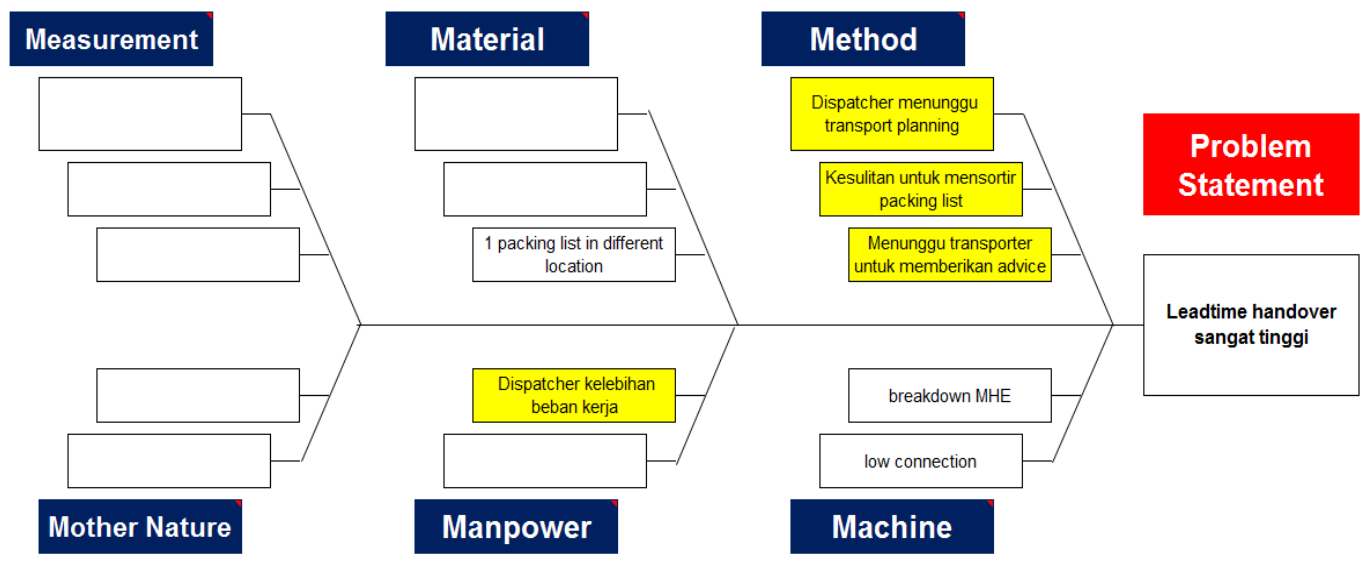

Gambar 2. Analisa sebab akibat leadtime handover yang sangat tinggi

Berdasarkan hasil brainstorming menggunakan diagram sebab akibat, maka diketahui penyebab atau akar masalah untuk segera dilakukan perbaikan antara lain :

1. Dispatcher menunggu transport planning selesai sangat lama

2. Kesulitan untuk sortir packing list berdasarkan nama customer

3. Menunggu transporter untuk memberikan advice alamat daily customer

4. Dispatcher kelebihan beban kerja.

\section{Rancangan solusi}

Setelah penyebab diketahui, maka selanjutnya brainstorming kembali dilakukan untuk menentukan rancangan solusi apa yang sesuai untuk memecahkan masalah dari penyebabpenyebab tersebut. Hasil brainstorming tersebut dapat dilihat pada gambar mind mapping dibawah ini :

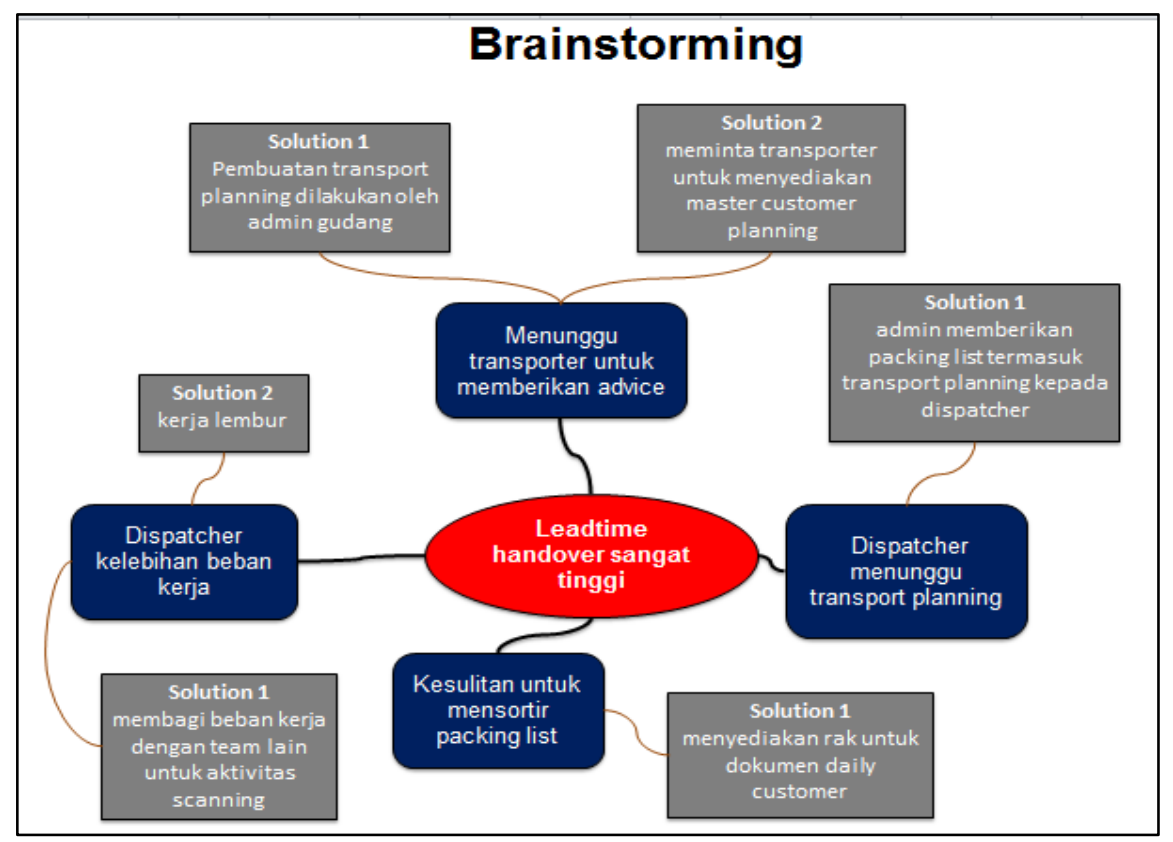

Gambar 3. Brainstorming rancangan solusi 
Lalu dari masing-masing solusi tersebut,dilakukan analisa prioritas menggunakan tabel effort benefit matrix, untuk memprioritaskan eksekusi dari masing-masing solusi. Analisa ini juga sebagai pertimbangan bagi pihak manajemen untuk persetujuan dan bahan pengambilan keputusan untuk setiap solusi yang akan dijalankan. Berikut hasil analisa effort benefit matrix :

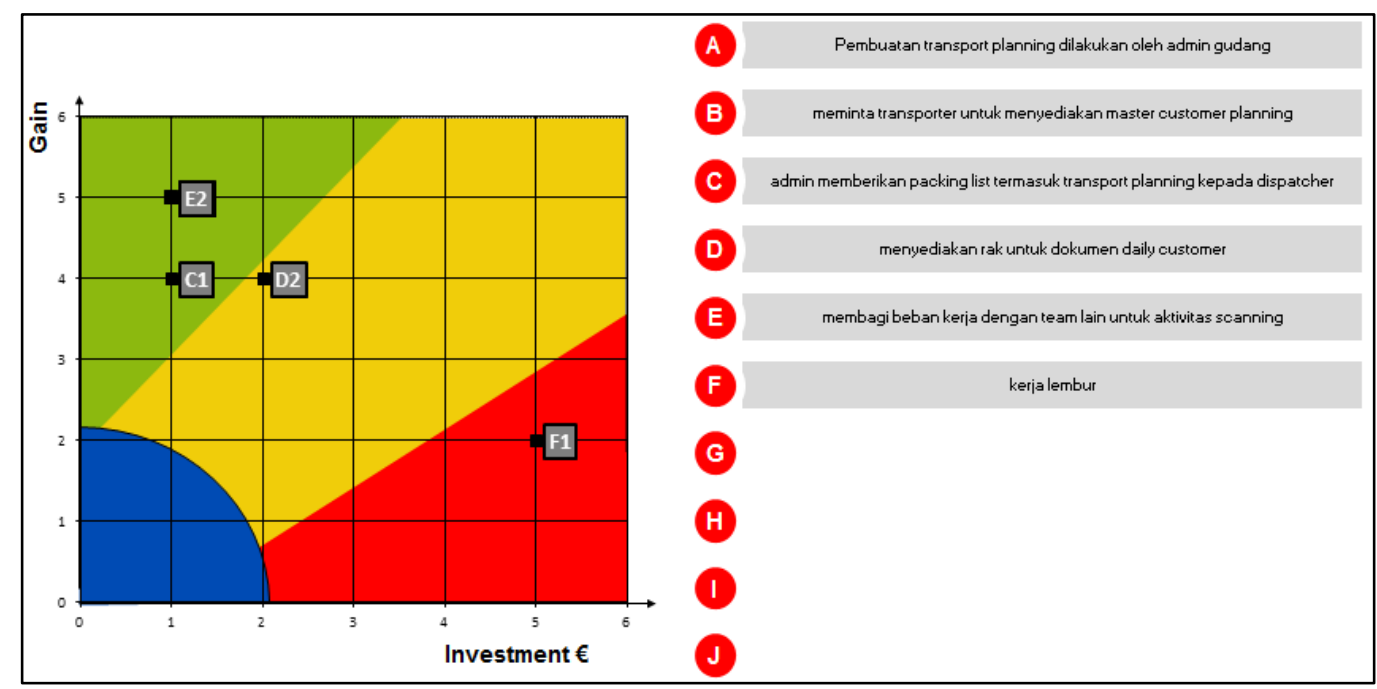

Gambar 4. Analisa effort benefit matrix

Dari tabel analisa effort benefit matrix, dapat diihat bahwa rancangan solusi yang akan dieksekusi antara lain :

Tabel 2. Rancangan solusi

\begin{tabular}{|c|l|}
\hline No & \multicolumn{1}{|c|}{ Rancangan Solusi } \\
\hline 1 & Pembuatan transport planning dilakukan oleh admin gudang \\
\hline 2 & meminta transporter untuk menyediakan master customer planning \\
\hline 3 & admin memberikan packing list termasuk transport planning kepada dispatcher \\
\hline 4 & menyediakan rak untuk dokumen daily customer \\
\hline 5 & membagi beban kerja dengan tim lain untuk aktivitas scanning \\
\hline
\end{tabular}

\section{Eksekusi solusi}

Langkah ini merupakan bagian dari tahap Do, dimana solusi yang sudah didapat dari analisa dan brainstorming di eksekusi. Daftar solusi yang harus dieksekusi antara lain :

\begin{tabular}{|c|c|c|c|c|c|}
\hline Cause & Overview of actions & Who & Deadline & Status & Comments \\
\hline \multirow[t]{2}{*}{$\begin{array}{l}\text { waiting transprter to advice } \\
\text { daily customer address }\end{array}$} & $\begin{array}{l}\text { create Transport Planning include customer address by } \\
\text { admin }\end{array}$ & Rio & $2 / 15 / 2018$ & Terminated & \\
\hline & $\begin{array}{l}\text { ask to transporter to provide master customer dealer } \\
\text { planning }\end{array}$ & Isom & $2 / 15 / 2018$ & Terminated & \\
\hline $\begin{array}{l}\text { Dispatcher waiting for } \\
\text { complete transport planning }\end{array}$ & $\begin{array}{c}\text { admin drop packing list include completed transport } \\
\text { planning }\end{array}$ & Ferrizal & $3 / 10 / 2018$ & Terminated & \\
\hline \multirow[t]{2}{*}{$\begin{array}{l}\text { difficult to find packing list by } \\
\text { daily customer }\end{array}$} & provide shelving for dalily customer document & Ferrizal & $3 / 10 / 2018$ & Terminated & \\
\hline & $\begin{array}{c}\text { admin sort and put away packing list into the shelving } \\
\text { by daily customer }\end{array}$ & Rio & $3 / 10 / 2018$ & Terminated & \\
\hline job overload for dispatcher & job sharing to team inbound for scanning activities & Ferrizal & $3 / 6 / 2018$ & Terminated & \\
\hline
\end{tabular}

Gambar 5. Daftar implementasi solusi 


\section{E. Memeriksa hasil}

Memeriksa hasil merupakan realisasi dari tahap Check, untuk melihat sejauh mana hasil yang didapat dan efek lain yang muncul setelah solusidi eksekusi.

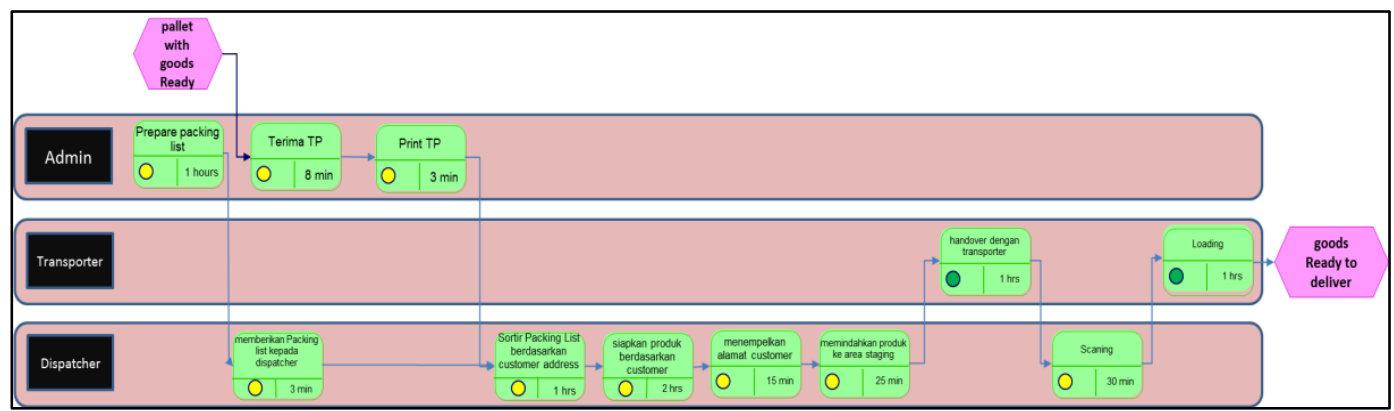

Gambar 6. Alur proses dan leadtime proses handover setelah improvement

Dari gambar diatas dapat dilihat bahwa terdapat beberapa dampak setelah pelaksanaan solusi, antara lain :

1. Aktivitas menunggu advice transport planning dari transporter dapat dihilangkan

2. Mengurangi lamanya waktu sortir dokumen dari 60 menit menjadi 15 menit

3. Mengurangi waktu persiapan produk dari 120menit menjadi 60 menit

4. Mengurangi lamanya waktu scaning dari 30 menit menjadi 15 menit

5. Sehingga berdampak pada penurunan leadtime proses handover dari 1161 menit menjadi 265 menit.

Jika kita melihat perbandingan leadtime antara kondisi sebelum improvement, target improvement, dan setelah improvement dapat dilihat pada tabel dibawah ini :

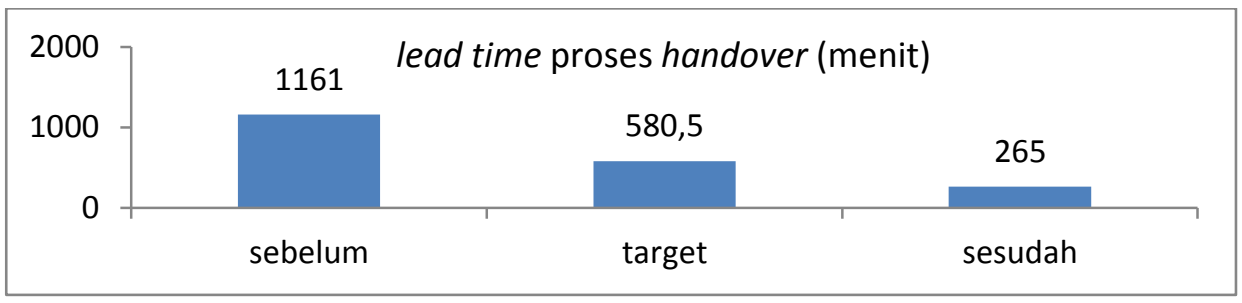

Gambar 7. Diagram perbandingan leadtime

Tabel diatas menunjukkan bahwa terjadi penurunan leadtime dari kondisi sebelum improvement dan setelah improvement sebesar $77 \%$.

Dampak lain yang muncul setelah solusi di eksekusi yaitu :

1. Penumpukkan produk di area staging tidak berlangsung lama setiap harinya, seluruh proses handover sudah selesai dilakukan sebelum pukul 16.00 Wib.

2. Memudahkan operator melakukan sortir dokumen, sehingga membuat operator merasa nyaman dalam bekerja.

\section{F. Implementasi}

Implementasi merupakan tahap Action pada metode PDCA, realisasi dari langkah implementasi ini antara lain :

1. Pembuatan work instruction untuk alur kerja baru atau alur kerja setelah improvement.

2. Melakukan monitoring mingguan untuk transport planning.

3. Menentukan topik improvement selanjutnya yaitu mengurangi pemborosan transportasi pemindahan produk menuju staging. 


\section{KESIMPULAN DAN SARAN}

Berdasarkan hasil penelitian yang dilakukan dapat disimpulkan bahwa impementasi continuous improvement menggunakan metode PDCA di PT. ABC berjalan efektif untuk memecahkan masalah yang ada di operasional. Dari studi kasus yang dilakukan pada proses handover menunjukkan dampak yang didapat antara lain :

1. Reduksi leadtime proses handover dari 1.161 menit menjadi 265 menit atau penurunan leadtime sebesar $77 \%$

2. Seluruh proses handover sudah selesai dilakukan sebelum pukul $16.00 \mathrm{Wib}$, atau berdampak pada penurunan jumlah inventory di area staging

3. Operator merasa nyaman dalam melakukan sortir dokumen yang dibutuhkan

Adapun saran dari hasil penelitian ini antara lain :

1. Perusahaan harus fokus terhadap pemecahan masalah yang menjadi sorotan pelanggan

2. Budaya continuous improvement digalakkan disemua lini perusahaan, agar terliat dampak yang sangat signifikan.

\section{DAFTAR PUSTAKA}

Alyoubi, M. Alqahtani, J \& Aziz, A, A (2017) Quality Improvement Methodologies - PDCA Cycle and Six Sigma in E-Learning System, International Advanced Research Journal in Science, Engineering and Technology, Vol.4, Issue. 5, ISSN : 2393- 8021

Blagojevic, M \& Micic, Z (2013) Adapting E-course Using Data Mining Techniques - PDCA Approach and Quality Spiral, Initernational Journal of Quality Research 7(3) 3 -14, ISSN $1800-6450$

Chakraborty,A (2016) Improtance of PDCA cycle for SMEs, SSRG International Journal of Mechanical Engineering, Vol.3, Issue.5, ISSN : 2348 - 8360

Dahlgaard, J, J., Kristensen, K \& Kanji, G, K (1998) Foundamental of Total Quality Management, Process Analysis and Improvement. Taylor \& Francis Group : London.

Gidey E, Jilcha K, Beshah B, Kitaw D (2014) The Plan-DO-Check-Act Cycle of Value Addition, The International Open Access Industrial Engineering \& Management, Vol.3, Issue.1, ISSN : $2169-0316$

Gupta, N (2013). An Overview on Six sigma : Quality Improvement Program, International Journal of Technical Research and Application, e-ISSN : 2320-8163, Vol. 1, Issue 1, PP. $29-39$

Juran J M, Godfrey A B (1999) Juran's Quality handbook: fifth edition, McGraw Hill: NewYork. 
